\title{
FAKTOR-FAKTOR PELAYANAN PRIMA YANG MEMPENGARUHI KEPUASAN SISWA PADA MENTARI CERDAS BANJARMASIN
}

\author{
SYAFRIL, MUHAMMAD FAHMI, NETI ROSIANA FADILAH \\ ASMI Citra Nusantara Banjarmasin \\ syafri199riau@gmail.com
}

\begin{abstract}
This study aims to determine the factors of excellent service that influence the satisfaction of tutoring students at Mentari Cerdas Banjarmasin. The population and sample in this study were tutoring students at Mentari Cerdas Banjarmasin. The sample in this study was 48 students by filling out research questionnaires. The sampling technique used in this research is random sampling. namely the sampling technique based on population members who happen to be met and are willing to be respondents. This research is a quantitative descriptive research, which is a research method based on the philosophy of positivism, which is used to examine a particular population or sample. Judging from the objectives, this research is included in the research of hypothesis testing. A hypothesis is a temporary answer to a research problem whose truth still needs to be tested

Keywords: Excellent Service, Student Satisfaction, Tutoring, Influence, Sampling
\end{abstract}

\begin{abstract}
Abstrak: Penelitian ini bertujuan untuk mengetahui Faktor-Faktor Pelayanan Prima Yang Mempengaruhi terhadap Kepuasan Siswa Bimbingan Belajar di Mentari Cerdas Banjarmasin Populasi dan sampel dalam penelitian ini adalah siswa bimbingan belajar di Mentari Cerdas Banjarmasin. Sampel dalam penelitian ini adalah 48 siswa dengan mengisi angket penelitian. Teknik pengambilan sampel yang digunakan dalam penelitian ini adalah random sampling. yaitu teknik pengambilan sampel berdasarkan anggota populasi yang kebetulan ditemui dan bersedia menjadi responden. Penelitian ini merupakan penelitian deskriptif kuantitatif yaitu suatu metode penelitian yang didasarkan pada filosofi positivisme, yang digunakan untuk meneliti populasi atau sampel tertentu. Dilihat dari tujuannya, penelitian ini termasuk dalam penelitian pengujian hipotesis. Hipotesis adalah jawaban sementara dari suatu masalah penelitian yang kebenarannya masih perlu diuji
\end{abstract}

Kata Kunci: Pelayanan Prima, Kepuasan Siswa, Bimbingan Belajar, Pengaruh, Sampel

\section{A. Pendahuluan}

Lembaga Kursus dan Pelatihan (LKP) merupakan satuan Pendidikan Luar Sekolah atau Nonformal (PNF) yang diselenggarakan bagi masyarakat yang memerlukan bekal pengetahuan, keterampilan, kecakapan hidup dan sikap untuk mengembangkan diri, bekerja mencari nafkah, mengembangkan profesi dan atau melanjutkan ke jenjang pendidikan yang lebih tinggi. Berdasarkan Undang- Undang Sisdiknas No. 20 tahun 2003 Pasal 26 Ayat 5 disebutkan bahwa kursus dan pelatihan adalah bentuk pendidikan berkelanjutan untuk mengembangkan kemampuan peserta didik dengan penekanan pada penguasaan keterampilan, standar kompetensi, pengembangan sikap kewirausahawan serta pengembangan kepribadian profesional. Bimbingan Belajar untuk selanjutnya disingkat dengan Bimbel, termasuk salah satu dari berbagai jenis Lembaga Kurusu dan Pelatihan (LK) sebagaimana disebutkan dalam UU Sisdiknas 2003 tersebut. Berdasarkan penjelasan tersebut dapat disimpulkan bahwa Bimbel adalah suatu lembaga Pendidikan Non Formal (PNF) yang keberadaannya telah diakui oleh Pemerintah (Indonesia, 2010).

Perkembangan teknologi digital internet menciptakan sebuah persaingan yang semakin ketat pada sektor layanan jasa bimbingan belajar bukan lagi sebatas persaingan produk tetapi sudah pada sistem pelayanan dan sistem pembelajaran. Beberapa usaha bimbingan belajar baik yang reguler maupun yang private mengemas jasa mereka agar menarik para konsumen. Saat ini muncul berbagai jasa bimbingan belajar dengan platform yang modern dengan media pembelajaran daring mengunakan aplikasi smartphone canggih. Bimbingan belajar

10 Lembaga Penelitian dan Penerbitan Hasil Penelitian Ensiklopedia $\quad$ E-ISSN: 2657-0300

P-ISSN: 2657-0319 
konvensional harus berhadapan head to head dengan bimbingan belajar daring tersebut untu memperebutkan pangsa pasar yang semakin melemeah akibat covid-19, disaat adanya pelarangan berkumpul dalam suatu pertemuan.

Fenomena aplikasi belajar daring ini diprediksi dapat mempengaruhi usaha bimbingan belajar (bimbel) di Banjarmasin. Bagaimana tidak, aplikasi belajar ini hadir dengan menawarkan harga yang lebih murah, dan konten belajar yang lengkap seperti try out, dan les privat. Selain itu, konten yang tersedia untuk berbagai jenjang mulai dari SD, SMP dan SMA sesuai dengan kurikulum nasional dan dirancang khusus oleh pengajar terbaik dan berpengalaman (master teacher). yang kemamuanya ini dapat diunduh secara langsung hanya melalui smartphone saja. Mungkin aplikasi belajar daring saat ini masih baru dan masih bisa dilakukan oleh anak-anak sekolah yang dapat dikatakan 'mandiri', artinya dapat belajar tanpa melalui pengawasan. Tetapi untuk bimbel masih punya kans di hati para orangtua murid, khususnya anak-anak SD dan SMP yang masih perlu pengawasan. Masih banyak anak-anak les private yang merasa nyaman dengan guru nyata ada di depan mereka, dengan begitu mereka jadi benar-benar belajar seara serius dan dapat berdialog secara langsung.

Bimbingan belajar merupakan sebuah entitas bisnis yang bergerak di bidang jasa. Dengan kata lain, bimbingan belajar merupakan sebuah entitas bisnis yang berorientasi profit (profit oriented) dengan jasa konsultasi belajar sebagai produk utamanya. Sebagai lembaga pendidikan informal, bimbingan belajar memiliki peran dan tanggung jawab terhadap dunia pendidikan yaitu mendukung program belajar nasional dan berusaha meningkatkan prestasi belajar siswa (Umam \& Hisyam, 2017). Bimbingan belajar dan sekolah sama-sama berperan serta memajukan dunia pendidikan nasinal. Diantara keduanya, sekolah dan bimbingan belajar memiliki hubungan yang saling menguntungkan (symbiosis mutualisme), dalam meningkatkan mutu anak didik agar mampu bersaing dalam mendapatkan sekolah lanjutan favorite setelah lulus nantinya. Sekolah merupaan mitra utama jasa bimbingan belajar untuk mendapatkan siswa dari sekolah tersebut. Siswa merupakan enduser dari jasa bimbingan belajar byang merupakan pangsa pasar utama sehingga produk yang ditawarkan merupakan kebutuhan dari siswa yaitu jasa pelayanan konsultasi dan bimbingan belajar.

Saat ini sekolah merupakan hal yang sangat penting bagi anak-anak dan remaja di dunia, termasuk di Indonesia. Sekolah menerapkan standar tinggi yang harus diraih oleh peserta didik yang dikenal dengan standar ketntuan minimun setiap ujiannya yang tertera di dalam rapor siswa. Jika nilai berada dibawah nilai ketentuan minimun maka siswa diwajikan untuk mengulang (remedial) sampai nilai tercukupi. Kriteria ketentuan kompetensi dasar nilai pada masing-masing mata pelajaran ditentukan oleh sekolah biasanya diatas 75\% (Rizal \& Paujiah, 2018). Tingginya ketentuan minimun tersebut membuat siswa menambah jam pelajarannya di luar sekolah dengan mengikuti bimbingan belajar baik secara daring maupun konvensional seperti les private, kursus dan paket bimbingan belajar.

Ketakutan siswa tidak lulus Ujian Akhir Nasional (UAN) dan Ujian Akhir Sekolah Bersama Nasional (UASBN) merupakan kesempatan emas bagi lembaga bimbingan belajar untuk meraup sebesar-besarnya dari bisnis pendidian ini. Ketakutan siswa dan orang tua akan ketidaklulusan ini menimbulkan kebutuhan yang tinggi terhadap pelajaran tambahan. Belum lagi keinginan siswa untuk masuk ke perguruan tinggi favorit (Umam \& Hisyam, 2017). Untuk menjaring siswa dan orang tua yang ingin anaknya mendapatkan pelajaran tambahan pada lembaga jasa bimbingan belajar maka diperlukan suatu strategi yang efektif merebut pangsa pasar. Saat ini banya lembaga bimbingan belajar yang menawarkan berbagai jenis program dan metode pembelajaran yang menarik agar siswa antusias dan memilih bimbingan belajar mereka. Menurut Zeithaml (1996), faktor terpenting yang menentukan keberhasilan organisasi adalah kemampuan organisasi memberikan layanan. Keberhasilan organisasi untuk pencapaian pangsa pasar (market share) yang tinggi sangat ditentukan oleh pendekatan yang digunakan organisasi. Salah satu pendekatan kualitas jasa yang banyak digunakan sebagai acuan dalam riset pemasaran adalah model SERVQUAL (Service Quality). Kompetisi dengan intensitas tinggi dan cepat menuntun bisnis jasa untuk mencari cara yang menguntungkan bagi mereka, dan salah satu strategi yang sangat kompeten untuk bisa sukses 
adalah dengan menghadirkan high service quality. Kualitas layanan yang baik akan mempengearuhi konsumen dalam mengambil keputusan membeli atau mengunakan suatu produk (Syafril, 2019)

Dalam menghadapi persaingan yang kompetitif bimbingan belajar Mentari Cerdas Banjarmasin memberikan pelayanan prima (servie excellent) untuk menjaga kelangsungan hidup usahanya karena dengan pelayanan prima akan meningkatkan loyalitas siswa agar tetap belajar dan bertahan sampai mereka lulus. Beerapa dimensi pelayanan prima yang diberikan kepada siswa bimbel seperti Kecekatan pelayanan (responsiveness), Pembelajaran mudah dipahami (reliabelity), Tentor intens pada siswa (empathy), Komunikasi yang baik (responsiveness), Ruang belajar bersih dan nyaman (tangible), Pembelajaran sesuai kurikulum (assurance), Mendidik attitude siswa (emphaty), Peningkatan nilai siswa di sekolah (assurance), Tentor yang berpengalaman (reliabelity) dan Administrasi yang mudah dan murah (responsiveness). Pelayanan prima (Sevice Excellent) adalah suatu usaha untuk membantu menyediakan atau mengurus apa yang diperlukan oleh konsumen.

Menurut Lovelock (2005), sebuah pelayanan yang baik dirancang dan disesuaikan dengan kebutuhan pelanggan dengan didasarkan atas sejumlah persyaratan yang telah menjadi tujuan penting bagi pelayanan organisasi. Proses pelayanan menjelaskan urutan dan metode yang dilakukan dalam system operasi pelayanan dimana pegawai berkerja dan terkoneksi dengan pegawai lainnya untuk secara bersama-sama menciptakan pengalaman pelayanan yang optimal sehingga pelanggan akan memberikan penghargaan. Adapun menurut Schiffman dan Kanuk (2004), menyataan pelayanan merupakan suatu hal yang penting, sebab peningkatan daripada pelayanan itu sendiri dapat meningkatkan kepuasan pelanggan. Pelayanan prima menurut Lukman (2000), merupakan suatu kegiatan yang terjadi dalam interaksi langsung antara seseorang dengan orang lain atau mesin secara fisik, dan menyediakan kepuasan pelanggan. Sedangkan menurut Ratminto dan Winarsih (2005), pelayanan adalah suatu aktivitas atau serangkaian aktivitas yang bersifat tidak kasat mata yang terjadi akibat adanya interaksi antara pelanggan dengan pegawai atau hal-hal lain yang disediakan oleh perusahaan. Pemberi pelayanan yang dimaksudkan untuk memecahkan permasalahan pelanggan. Menurut Priansa, (2017:54), pelayanan prima (service quality) adalah suatu sikap atau cara karyawan dalam melayani pelanggan secara memuaskan. Secara garis besar ada 4 (empat) dimensi pokok dalam konsep ini, yaitu kecepatan, ketepatan, keramahan, dan kenyamanan. Komponen yang berjumlah empat tersebut merupakan satu kesatuan pelayanan yang terintegrasi, artinya pelayanan atau jasa menjadi tidak excellent bila ada salah satu atau lebih komponen yang kurang. Disamping itu, keempat komponen ini akan lebih bermakna bila didukung oleh suatu strategi pelayanan yang tepat, karena strategi pelayanan merupakan arahan dan pedoman bagi organisasi untuk memberikan pelayanan terbaikannya.

Konsep kualitas pelayanan yang populer dikemukakan oleh (Ananthanarayanan Parasuraman, Zeithaml, \& Berry, 1994) dengan Model SERVQUAL yang memiliki lima dimensi pengukuran kualitas pelayanan yang sering disingkat aspek TERRA sampai saat ini secara umum telah banyak digunakan pada perusahaan jasa. Kelima dimensi itu adalah Tangible, Emphaty, Reliability, Responsivenes, Assurance. Riset eksploratori yang Parasuraman lakukan untuk meneliti kualitas jasa dan menentukan faktor-faktor yang mempengaruhinya menghasilkan 5 (lima) dimensi kualitas jasa atau pelayanan, yaitu; 1) Tangibles yaitu fasilitas fisik perusahaan mulai dari perlengkapan, sarana komunikasi dan lainnya yang dapat dilihat langsung oleh pelanggan. 2) Emphaty yaitu pemahaman seksama tentang kebutuhan yang diharapkan pelanggan. 3) Reliability yaitu kemampuan untuk memberi pelayanan yang cepat, tepat, dan memuaskan oleh perusahaan. 4) Responsiveness yaitu pemberian pelayanan atau jasa dengan tanggap oleh perusahaan. 5) Assurance terkait dengan kesopanan staff/karyawan, dan sifat dapat dipercayanya staff/karyawan perusahaan oleh pelanggan.

Penelitian yang dilakaukan (Khaliq, 2019) mengenai Pengaruh Kualitas Pelayanan Terhadap Kepuasan Nasabah Bank Syariah Mandiri di Banjarmasin Kalimantan Selatan 
mengunakan variabel CARTER (Compliance, Assurance, Reliability,Tangible, Empathy, Responsiveness). CARTER adalah instrumen yang dapat digunakan untuk mendefinisikan dan mengukur kualitas layanan jasa dan untuk membuat alat penilaian kualitas yang berguna, model ini memiliki enam dimensi yang dikemukan oleh (Othman \& Owen, 2001) sebagai berikut: a) Compliance yang berarti kemampuan untuk memenuhi hukum Islam dan beroperasi berdasarkan prinsip perbankan dan ekonomi Islam; b) Assurance adalah pengetahuan dan kesopanan karyawan dan kemampuan mereka untuk menyampaikan kepercayaan dan kepercayaan diri. Ini juga mencakup komunikasi verbal dan tertulis antara staf bank dan pelanggan; c) Reliability untuk melakukan layanan yang dijanjikan, ketergantungan dan akurasi; d) Tangibles yang berarti penampilan fasilitas fisik, peralatan, personel, dan alat komunikasi; e) Emphaty adalah perhatian individual yang disediakan bank syariah untuk para pelanggannya; dan f) Responsiveness adalah kesediaan untuk membantu pelanggan dan memberikan layanan yang cepat.

Hasil penelitian (Khaliq, 2019), seluruh variabel kualitas pelayanan CARTER menunjukkan hasil yang signifikan dalam mempengaruhi kepuasan nasabah. Jika diurutkan maka faktor dimensi kualitas pelayanan yang mempengaruhi kepuasan nasabah secara berturut-turut dari yang paling besar adalah compliance, reliability, responsiveness, tangibles, emphaty, kemudian assurance. Kepuasan konsumen adalah keadaan yang dicapai bila produk sesuai dengan kebutuhan atau harapan konsumen dan bebas dari kekurangan. Menurut Kotler dan Amstrong (2001) kepuasan konsumen adalah sejauh mana anggapan kinerja produk memenuhi harapan pembeli. Bila kinerja produk lebih tinggi ketimbang harapan pelanggan, maka pembelinya merasa puas atau amat gembira. Perbedaan antara pelayanan yang diterima dengan yang diharapkan (kepuasan), harus diminimalisasi agar hasilnya pelanggan bisa puas, yaitu dengan mengelola kesenjangan-kesenjangan yang terjadi pada penyerahan jasa. Penyedia harus memperbaiki kualitas jasa setiap saat dan semakin agresif untuk mengadakan penelitian akan kepuasan dan ketidak puasan pelanggan. Menurut Zeithaml (1999) kepuasan konsumen dipengaruhi oleh persepsi atas kualitas jasa, persepsi atas harga, serta faktor situasional dan personal. Kepuasan konsumen dipengaruhi oleh kualitas produk dan pelayanan yang diberikan pada pelanggan dalam proses penyerahan jasa.

Kepuasan pelanggan telah menjadi konsep sentral dalam teori dan praktek pemasaran, serta merupakan salah satu tujuan esensial bagi aktivitas bisnis. Kepuasan pelanggan berkontribusi kepada sejumlah aspek kruisal, seperti terciptanya loyalitas pelanggan, meningkatkan reputasi perusahaan, berkurangnya biaya transaksi masa depan, dan meningkatnya efisiensi dan produktivitas karyawan. Selain itu kepuasan pelanggan juga dipandang sebagai salah satu indikator terbaik untuk masa depan. Pelanggan yang merasa puas akan membeli ulang, dan mereka memberitahu orang lain mengenai pengalaman baik tentang paket pembelajaran tersebut.

Penelitian yang dilakukan oleh (Asih, 2016) tentang Pengaruh Pelayanan Prima (Service Excellence) Terhadap Kepuasan Pelangan Salon Agata Singgaraja diketahui bahwa secara parsial Kemampuan, Sikap, Penampilan, Tindakan dan Tanggungjawab mempunyai pengaruh yang positif dan signifikan terhadap Kepuasan Pelanggan, sedangkan Perhatian tidak mempunyai pengaru terhadap Kepuasan Pelanggan Salon Agata Singgaraja. Secara simultan semua variabel independen mempunya pengaru positif dan signifika terhadap kepuasan pelanggan Salon Agata Singgaraja. Hasil penelitian yang dilakukan oleh (Nofirza \& Indrayani, 2011) menyatakan kualitas pelayanan berpengaruh terhadap kepuasan pasien Rumah Sakit Arifin Ahmad Pekanbaru. Adapun penelitian yang dilakukan oleh (Mulyono, 2019), dinyatakan kepausan pasien akan meningkat seiring dengan meningkatnya kualitas pelayanan Rumah Sakit Medika Permata Hijau Jakarta dengan aspek fisik (tangibele), kehandalan (reliability), ketanggapan (responsibility), kepastian (assurance) dan emphati (emphaty) secara signifikan berurutan menpengaruhi kepuasan pasien. Penelitian lain yang dilakukan oleh (Tho'in, 2018) tentang Pengaruh Kinerja Pelayanan (service performance) Terhadap Loyalitas Mahasiswa Dengan Kepuasan sebagai Moderaot dapat disimpulkan bahwa kinerja pelayanan berpengaruh secara signifikan terhadap kepuasan, loyalitas mahasiswa Sekolah Tinggi Ilmu 
Ekonomi AAS. Adapun penelitian yang dilakukan oleh (Suadmodjo, 2017) dimana kualitas layanan memiliki pengaruh terhadap kepuasan pelanggan Cafe Zybricx Coffe \& Cantina dengan variabel reliabelity sebagai dimensi yang paling dominan sedangkan kualitas produk sebagai faktor yang paling dominan.

Dari beberapa hasil penelitian terdahulu maka dalam penelitian ini dimensi Pelayanan Prima yang digunakan dalam kuisiner penelitian yang dibuat secara sederhana sesuai karakteristik responden yang masih menempuh pendidikan dasar mulai dari Sekolah Dasar (SD), Sekolah Menengah Pertama (SMP) dan Sekolah Menengah Atas (SMA Dari penjelasan diatas maka kerangka konseptual penelitan ini dapat digambarkan sebagai berikut:

Tabel. 1

Kerangka Konseptual

\begin{tabular}{|c|c|c|}
\hline Pelayanan Prima $(\mathrm{X})$ & & \multirow[t]{2}{*}{ Kepuasan Siswa (Y) } \\
\hline Indikator: & & \\
\hline Kecekatan Pelayanan & $\mathrm{X} 1.1$ & \multirow{10}{*}{$\begin{array}{l}\text { Suatu keadaan dimana } \\
\text { kebutuhan, keinginan dan } \\
\text { harapan siswa bimbel dapat } \\
\text { terpenuhi melalui jasa atau } \\
\text { produk yang ditawarkan. }\end{array}$} \\
\hline Proses Pembelajaran Mudah Dipahami Siswa & $\mathrm{X} 1.2$ & \\
\hline Tentor Intens Terhadap Siswa & $\mathrm{X} 1.3$ & \\
\hline Komunikasi Yang Baik Antara Tentor dan Siswa & $\mathrm{X} 1.4$ & \\
\hline Ruang Belajar Bersih dan Nyaman & $\mathrm{X} 1.5$ & \\
\hline $\begin{array}{l}\text { Pembelajaran Sesuai Dengan Kurikulum } \\
\text { Pendidikan }\end{array}$ & $\mathrm{X} 1.6$ & \\
\hline Membantu Mendidik Attitude Siswa & $\mathrm{X} 1.7$ & \\
\hline Tentor Kompeten Dalam Menyampaikan Materi & $\mathrm{X} 1.8$ & \\
\hline Peningkatan Nilai Siswa Di Sekolah & $\mathrm{X} 1.9$ & \\
\hline Administrasi Mudah dan Murah & $\mathrm{X} 1.10$ & \\
\hline
\end{tabular}

Sumber: data diolah, 2022

\section{B. Metodologi Penelitian}

Menurut Umar (2008:5), desain penelitian merupakan kerangka kerja untuk merinci hubungan-hubungan antara variabel terkait dalam suatu penelitian. Ditinjau dari tujuannya, penelitian ini dikategorikan kedalam penelitian pengujian hipotesis. Hipotesis adalah jawaban sementara atas suatu permasalahan penelitian yang kebenaran masih perlu diuji (Kountur, 2009:67). Objek penelitian ini adalah siswa bimbingan belajar Mentari Cerdas Banjarmasin. Populasi adalah subjek dan objek yang memiliki karakter dan kualitas tertentu yang diterapkan untuk dipelajari, yang kemudian ditarik menjadi sebuah penelitian. Sampel adalah bagian dari keseluruhan serta karakteristik yang dimiliki oleh sebuah sebuah populasi yang dianggap dapat mewakili seluruhnya untuk diteliti. Teknik pengambilan sampel yang digunakan dalam penelitian ini adalah random sampling. yaitu teknik pengambilan sampel berdasarkan anggota populasi yang kebetulan ditemui dan bersedia menjadi responden. Penelitian ini bersifat deskriptif kuantitatif yang merupakan metode penelitian yang berlandaskan pada filsafat positivisme, digunakan untuk meneliti pada populasi atau sampel tertentu Alat uji analisis data yang digunaan dalam penelitianini adalah SPSS versi 23 .

\section{Hasil Dan Pembahasan}

Analisis diskriptive memberikan gambaran tentang data yang diperoleh. Diskripsi data analisis deskriptif dilakukan untuk mengatahui karakter sampel. Statistik deskriptif suatu data yang dilihat dari nilai rata-rata, standar deviasi, maksimum, minimum, yang didapat dari variabel dependen dan independen. Hasil analisis deskriptif penelitian sebagai berikut:

Tabel. 2 Diskriptive Demograpi Responden

\begin{tabular}{|ll|llll|}
\hline Profile & & Frequency & Percent & Valid Percent & Cumulative Percent \\
\hline Gender & Pria & 20 & 41,7 & 41,7 & 41,7 \\
& Wanita & 28 & 58,3 & 58,3 & 100,0 \\
\hline \multirow{5}{*}{14} & Lembaga Penelitian dan Penerbitan Hasil Penelitian Ensiklopedia & E-ISSN: 2657-0300 \\
& & & P-ISSN: 2657-0319
\end{tabular}




\begin{tabular}{|ll|llll|}
\multirow{4}{*}{ Usia } & Total & 48 & 100,0 & 100,0 & \\
& $06-10$ thn & 8 & 16.7 & 16.7 & 16.7 \\
& $11-15$ thn & 31 & 64.6 & 64.6 & 64.6 \\
\multirow{4}{*}{ Pendidikan } & $16-18$ thn & 9 & 18.8 & 18.8 & 100 \\
& Total & 48 & 100 & 100 & 16.7 \\
& SD & 8 & 16.7 & 16.7 & 62.5 \\
& SMP & 30 & 62.5 & 62.5 & 100 \\
& SMA & 10 & 20.8 & 20.8 & \\
Paket & Total & 48 & 100 & 100 & 31.3 \\
Bimbel & 1 thn & 15 & & & 22.9 \\
& & & 31.3 & 31.3 & 43.8 \\
& 2 thn & 11 & 22.9 & 22.9 & 100 \\
& 3 thn & 21 & 43.8 & 43.8 & \\
\hline
\end{tabular}

Sumber: data kuesioner diolah, 2022

Dari data demograpi responden diatas dapat diketahui bahwa responden wanita lebih besar daripada pria yakni 58,3\% berbanding pria $41,7 \%$. Usia minimal yakni yang paling muda merupakan usia awal siswa masuk sekolah umur 06-10 tahun sebesar 16,7\% sedangkan usia yang paling mendominasi adalah usia 11-15 tahun diikuti usia 16-18 tahun sebesar $18.8 \%$. Tingkat pendidikan yang sedang ditempuh siswa berbanding lurus dengan usianya yakni SD sebesar $16.7 \%$ dan yang paling dominan siswa SMP sebesar $62.5 \%$ selanjutnya siswa SMA sebesar $20.8 \%$. Paket bimbel yang diambil oleh siswa mulai paket 1 tahun sebesar $31.3 \%$ yang 2 tahun sebesar $22.9 \%$ dan yang paling dominan diambil siswa paket 3 tahun sebesar $43.8 \%$ selanjutnya yang paling sedikit paket bimbel 4 tahun sebesar $2.1 \%$.

Dalam penelitian ini digunakan dua variabel penelitian yakni Pelayanan Prima dengan sepuluh (10) variable indikator sebagai variabel bebas dan Kepuasan Siswa sebagai variabel terikat. Dari uji statistik diskriptif diperoleh gambaran data statistik atas dua variabel tersebut sebagai berikut:

\begin{tabular}{|l|l|l|l|l|l|}
\hline \multicolumn{7}{|c|}{ Tabel. 3 Descriptive Statistics } \\
\hline & $\mathrm{N}$ & Minimum & Maximum & Mean & Std. Deviation \\
\hline Pelayanan Prima & 48 & 30 & 39 & 34,06 & 2,098 \\
\hline Kepuasan siswa & 48 & 9 & 12 & 10,88 & 1,024 \\
\hline Valid N (listwise) & 48 & & & & \\
\hline
\end{tabular}

Sumber: data SPSS diolah, 2022

Berdasarkan hasil data diatas dapat diketahui bahwa Pelayanan Prima nilai maksimal 39 dan nilai minimalnya 30 serta nilai rata-rata 34,06 dengan nilai standar deviasi 2,098. Dimana nilai rata-rata lebih besar dari nilai standar deviasi yaitu 34,06 > 2,08 yang menunjukkan bahwa nilai Pelayanan Prima cukup tinggi. Sedangkan nilai Kepuasan Siswa diketahui nilai maksimal sebesar 12 dan nilai minimal sebesar 9 dengan nilai rata-rata sebesar 10,88 dan nilai satandar deviasi sebesar 1,024. Hal ini menunjukkan bahwa tingkat kepuasan siswa cukup tinggi, dimana nilai rata-rata lebih besar dari nilai standar deviasinya yaitu 10,88 >1,024. Dari data yang disajikan diatas terlihat jelas bahwa rata-rata nilai mean lebih besar dari nilai standar deviasi. Standar deviasi merupakan cerminan dari rata-rata penyimpangan data dari mean. Standar deviasi dapat menggambarkan seberapa besar variasi data, dimana jika nilai standar deviasi lebih besar dari nilai mean berarti nilai mean merupakan refresentasi yang buruk dari keseluruhan data. Begitu sebaliknya jika nilai standar deviasi lebih kecil dari nilai mean berarti nilai mean merupakan refresentasi yang baik dari keseluruhan data.

\section{Uji Validitas dan Reliabilitas}

Uji Validitas. Uji validitas ini dilakukan untuk mengetahui tingkat kesahihan suatu kuesiner. Uji ini dilakuan dengan cara mengkorelasikan skor tiap butir kuesioner dengan skor 
totalnya. Semakin tinggi validitas suatu alat ukur, maka akan semakin tinggi pula ketepatan alat ukur tersebur mengenai sasaran. Uji validitas menurut Sugiyono ( 2016, 176) suatu instrument dikatakan valid berarti menunjukan alat ukur yang dipergunakan untuk mendapatkan data itu valid atau dapat digunakan untuk mengukur apa yang seharusnya diukur.

Tabel. 4 Uji Validitas

\begin{tabular}{|llll|}
\hline Variabel & rhitung & rtabel & keterangan \\
\hline X1 & 0.327 & \multirow{2}{*}{0.2787} & Valid \\
X2 & 0.325 & & Valid \\
X3 & 0.287 & & Valid \\
X4 & 0.424 & & Valid \\
X5 & 0.290 & & Valid \\
X6 & 0.417 & & Valid \\
X7 & 0.325 & & Valid \\
X8 & 0.545 & & Valid \\
X9 & 0.299 & & Valid \\
X10 & 0.302 & & Valid \\
\hline
\end{tabular}

Data SPSSdiolah, 2022

Dari tabel. 3 hasil uji validitas data diatas dapat diketahui nilai Pearseon Corelation pada variabel pelayanan prina $(X)$ diatas dengan nilai $r_{\text {tabel }}$ yakni 0.2787 dan nilai signifikansi sebesar 0,05, maka dapat dinyatakan bahwa data yang disajikan valid.

Uji Reliabilitas. Uji reliabilitas digunakan untuk mengukur suatu kuisioner yang merupakan indikator dari variabel. Suatu kuisioner atau angket dikatakan reliabel apabila jawaban seseorang sampel terhadap pernyataan bersifat konsisten atau stabil dari waktu ke waktu (Umar, 2002, 120). Uji reliabilitas akan dilakukan dengan menggunkan uji statistik cronbach alpha. Pengujian cronbach alpha digunakan untuk mengetahui tingkat kehandalan (reliabilitas) dari masing-masing kuesioner. Apabila niainya lebih besar dari $r_{\text {tabel }}$ maka hal ini mengidentifikasian bahwa semakin tinggi pula nilai konsistensi kehandalannya (reliabel). Dengan ketentuan bahwa variabel yang diteliti dikatakan reliabel apabila nilai cronbach alpha adalah di atas 0,5 Sugiyono (2009:235) dalam (Syafril, 2019).

Dari hasil uji statistik mengunakan SPSS maka diperoleh nilai Crobach Alpha sebesar 0,566 yang berarti nilainya lebih besar dari syarat minimal reliability sebesar o,5 dimana hasilnya menunjukkan $0,566>0,5$. Hal ini menidentifikasian bahwa instrumen yang digunakan dalam penelitian ini valid dan handal serta dapat digunakan untuk proses selanjutnya

Tabel. 5 Reliability Statistics

\begin{tabular}{|r|r|}
\hline Cronbach's Alpha & N of Items \\
\hline, 566 & \\
\hline
\end{tabular}

Sumber: Data SPSS, 2022

Uji Linearitas Sederhana. Uji regresi linear sederhaa menurut Sugiyono (2016, p261) dalam (Suadmodjo, 2017) menyatakan bahwa regresi sederhana di dasarkan pada hubungan fungsional ataupun kausal satu variabel independen dengan satu variabel dependen. Dengan dasar pengambiak keputusan dengan dua cara yaitu dengan perbandingan nilai sig dengan nilai probabilitas, dan perbandingan nilai t hitung dengan $\mathrm{t}$ tabel.

Perbandingan nilai sig dengan nilai probabilitas (nilai probabilitas $=0,05$ )

1. Jika nilai sig < nilai probabilitas, artinya variabel bebas berpengaruh secara signifikan terhadap variabel terikat.

2. Jika nilai sig > nilai probabilitas, artinya variabel bebas tidak berpengaruh secara signifikan terhadap variabel terikat.

Perbandingan nilai $t$ hitung dengan nilai $t$ tabel

1. Jika nilai $t$ hitung $>t$ tabel, maka artinya variabel bebas berpengaruh secara signifikan terhadap variabel terikat.

16 Lembaga Penelitian dan Penerbitan Hasil Penelitian Ensiklopedia $\quad$ E-ISSN: 2657-0300 
2. Jika nilai $\mathrm{t}$ hitung $<\mathrm{t}$ tabel, maka artinya variabel bebas tidak berpengaruh secara signifikan terhadap variabel terikat.

Tabel. 6 Hasil Pengolahan Data

\begin{tabular}{|c|c|c|c|c|c|}
\hline \multicolumn{2}{|c|}{ Variabel Regresi } & Koefisien & $t_{\text {hitung }}$ & Sig & Keterangan \\
\hline \multicolumn{2}{|l|}{ Konstanta } & 2,137 & & & \\
\hline \multicolumn{2}{|c|}{$\mathrm{X} 1$} & $-0,092$ & $-0,604$ & 0,550 & Tidak Sigmifikan \\
\hline \multicolumn{2}{|c|}{$\mathrm{X} 2$} & 0,004 & 0,024 & 0,981 & Tidak Sigmifikan \\
\hline \multicolumn{2}{|c|}{$\mathrm{X} 3$} & 0,357 & 1,959 & 0,058 & Tidak Sigmifikan \\
\hline \multicolumn{2}{|c|}{$\mathrm{X} 4$} & 0,116 & 0,740 & 0,464 & Signifikan \\
\hline \multicolumn{2}{|c|}{$\mathrm{X} 5$} & 0,033 & 0,233 & 0,817 & Tidak Sigmifikan \\
\hline \multicolumn{2}{|c|}{$\mathrm{X} 6$} & 0,081 & 0,509 & 0,614 & Tidak Sigmifikan \\
\hline \multicolumn{2}{|c|}{$\mathrm{X} 7$} & $-0,068$ & $-0,433$ & 0,667 & Tidak Sigmifikan \\
\hline \multicolumn{2}{|c|}{$\mathrm{X} 8$} & 0,332 & 1,783 & 0,083 & Signifikan \\
\hline \multicolumn{2}{|c|}{$\mathrm{X} 9$} & $-0,188$ & -1.175 & 0,247 & Signifikan \\
\hline \multicolumn{2}{|c|}{$\mathrm{X} 10$} & $-0,244$ & $-1,770$ & 0,085 & Signifikan \\
\hline$t_{\text {tabel }}$ & \multicolumn{5}{|l|}{$=1.67866$} \\
\hline $\mathrm{R}$ & \\
\hline R Square & $\begin{array}{l}=0.623 \\
=0.388\end{array}$ & & & & \\
\hline $\begin{array}{l}\text { Adjust R } \\
\text { Square }\end{array}$ & $=0.222$ & & & & \\
\hline
\end{tabular}

Sumer: data SPSS diolah, 2022

Menurut (Syafril \& Huda, 2015), dari hasil uji regresi sederhana diatas dapat dibuat persamaan linear penelitian ini adalah $\mathrm{Y}=2.137-0,092 \mathrm{X}_{1}+0,004 \mathrm{X}_{2}+0,357 \mathrm{X}_{3}+0,116 \mathrm{X}_{4}+$ $0.033 X_{5}+0,081 X_{6}-0,068 X_{7}+0,332 X_{8}-0,188 X_{9}-0,244 X_{10}+e$.

Dari hasil melakukan pengujian dengan alat ukur statistik SPSS versi 23 dierleh hasil sebagai berikut:

1. Nilai R sebesar 0.623 atau $62,3 \%$ adalah koefisien korelsi ganda yang menunjukkan tingkat hubungan antara variabel bebas Kecekatan Pelayanan (X1), Proses Pembelajaran Mudah Dipahami Siswa (X2), Tentor Intens Terhadap Siswa (X3), Komunikasi Yang Baik Antara Tentor dan Siswa (X4), Ruang Belajar Bersih dan Nyaman (X5), Pembelajaran Sesuai Dengan Kurikulum (X6), Pendidikan. Membantu Mendidik Attitude Siswa (X7), Kompeten Dalam Menyampaikan Materi (X80, Peningkatan Nilai Siswa Di Sekolah (X9), Administrasi Mudah dan Murah (X10) dengan Kepuasan Siswa (Y) dimana nilai korelasi tersebut menunjukkan tingkat hubungan sangat tinggi karena nilainya berada diantara 0.600-0.7999 menurut tabel, 6 dibawah ini:

Tabel .7 Interprestasi Koefisien Korelasi

\begin{tabular}{|l|l|l|}
\hline No & Interval Koefisien & Tingkat Hubungan \\
\hline 1 & $0.800-1.000$ & Sangat Tinggi \\
\hline 2 & $0.600-0.799$ & Tinggi \\
\hline 3 & $0.400-0.599$ & Sedang \\
\hline 4 & $0.200-0,399$ & Rendaah \\
\hline 5 & $0.000-0.199$ & Sangat Rendah \\
\hline
\end{tabular}

Sumber: Sugiyno (2010: 231)

2. Nilai R Square sebesar 0.388 adalah $\mathrm{R}$ kuadrat, yang menunjukkan bahwa variabel independenyang diambil dalam penelitian ini memiliki angka hubungan dengan variabel independen sebesar 38,8\% sehingga selebihnya sebesar $61,2 \%$ adalah variabel-variabel lain yang tidak dikemukan dalam penelitian ini. 
3. Adjust R Square model regresi ini adalah sebesar 0,222 yang menunjukkan bahwavariasi atau naik turunnya variabel dependen $(\mathrm{Y})$ dipengaruhi oleh variabel independen $(\mathrm{X})$ adalah sebsar $=22,2 \%$ yang berkorelasi positif.

\section{Penutup}

Berdasarkan hasil penelitian ini dapat diketahui bahwa faktor Komunikasi Yang Baik Antara Tentor dan Siswa (X4), Kompeten Dalam Menyampaikan Materi (X8), Peningkatan Nilai Siswa Di Sekolah (X9), Administrasi Mudah dan Murah (X10) berpengaruh signifikan terhadap Kepuasan Siswa bimbingan belajar Mentari Cerdas Banjarmasin. Sedangkan factor Kecekatan Pelayanan (X1), Proses Pembelajaran Mudah Dipahami Siswa (X2), Tentor Intens Terhadap Siswa (X3 Belajar Bersih dan Nyaman (X5), Pembelajaran Sesuai Dengan Kurikulum (X6), Pendidikan. Membantu Mendidik Attitude Siswa (X7), tidak berpengaruh sugnifikan terhadap Kepuasaan Siswa bimbingan belajar Mentari Cerdas Banjarmasin. Hal ini sesuai dengan karakteristik responden yang sebagian besar merupakan anak-anak yang masih menempuh pendidikan dasar mulai dari SD, SMP dan SMA. Hal ini juga dapat dilihat dari diskriptif demograpi responden yang masih berusia anak-anak mulai dari umur 6 tahun sampai dengan 18 tahun yang proses pengambilan keputusannya mengikuti bimbingan belajar tentu masih atas arahandari orang tuanya.

\section{Daftar Pustaka}

Asih, N. S. (2016). Pengaryh Pelayanan Prima (Service Excellence) Terhadap Kepuasan Pelangan Salon Agata Singgaraja. Jurnal Program Studi Pendidikan Ekonomi, 1-9.

Dahlan, A. dkk. (1995). Kamus Besar Bahasa Indonesia. Jakarta: Balai Pustaka.

Daryanto., \& Setyobudi, I. (2014). Konsumen Dan Pelayanan Prima. Yogyakarta: Gava Media.

Firmansyah, M. A. (2018). Prilaku Konsumen (sikap dan Pemasaran). Yogyakarta: Deepublish.

Indonesia, B. (2010). Pola Pembiayaan Usaha Kecil (PPUK) Komoditas Jasa Bimbingan Belajar. Jakarta: Bank Indonesia.

Iqbal, M. (2007). Pelayanan Yang Memuaskan. Jakarta: PT. Elex Media Komputindo.

Kountur, Ronny, 2009,Metode Penelitian untuk Penulisan Skripsi dan Tesis, Edisi Revisi, Penerbit PPM, Jakarta

Khaliq, R. (2019, Juni 29). Pengaruh Kualitas Pelayanan Terhadap Kepuasan Nasabah Bank Syaria Mandiri Di Banjarmasin Kalimantan Selatan. (I. Surakarta, Penyunt.) Jurnal Relevance, 2, 177-188.

Kotler, Philip. (2005) Manajemen pemasaran jilid 1 (11 $1^{\text {th }}$ ed.) (Benyamin Molan, Trans.). Jakarta, Indonesia: PT. Indeks.

Lovelock, Christopher \& Jochen Wirtz. (2004). Service marketing $5^{\text {th }}$ edition people, technology, strategy. New York : Pearson.

Mulyono, S. (2019, Desember). Analisis Kualitas Harga,Fasilitas, Customer Loyalty Terhadap Kepuasan Pasien Rawan Jalan Rumah Sakit Medika Permata Hijau Jakarta. (I. Surakarta, Penyunt.) Jurnal Relevan, 241-250.

Nofirza, \& Indrayani. (2011). Aplikasi Metode Kano Dalam Analisis Indikator Kualitas Pelayanan di Rumah SAkit Arifin Ahmad Pekanbaru. Jurnal, 9, 1-8.

Othman, A., \& Owen, L. (2001). The Multi Dimensionality of Carter Model to Measure Customer Service Quality (SQ) in Islamic Banking Industry: A Study in Kuwait Finance House. International Journal of Islamic Financial Services, 3(4), 1-12.

Parasuraman, Anantharanthan, Berry, L. L., \& Zeithaml, V. A. (1991). Perceived Service Quality as A Customer-Based Performance Measure: An Empirical Examination of Organizational Barriers Using an Extended Service Quality Model. Human resource management, 30(3), 335-364. 
Parasuraman, Ananthanarayanan, Zeithaml, V. A., \& Berry, L. L. (1994). Reassessment of Expectations as a Comparison Standard in Measuring Service Quality: Implications for

Further Research. Journal of marketing, 58(1), 111-124.

Priansa, D. J. (2017). Manajemen Pelayanan Prima. Bandung: Alfabeta.ksks,

Rizal, M., \& Paujiah, S. (2018, Maret). Strategi Pemasaan Pada Lembaga Bimbingan Belajar

Go Smart Banjarbaru. (S. P. Setia, Penyunt.) Jurnal Ilmu Ekonomi Bisnis, 77-86.

Suadmodjo, F. A. (2017). Pengaruh Kualitas Layanan Trhadap Kepuasan Pelanggan Cafe Zybricx Coffe \& Cantina. Jurnal Agora, 5.

Sugiyono, 1999,Statistik Untuk Penelitian, Cetkan 2, PT Alfabeta, Bandung ,2009,Manajemen Keuangan Untuk Praktisi Keuangan, Grassindo, Jakarta 2012,Metode Penelitian Bisnis, CV Alfabeta, Bandung

Schiffman, Leon,.\& Leslie Lazar Kanuk. (2004). Perilaku konsumen. PT Indeks, Jakarta

Syafril. (2019). Mengapa Memilih Pembiayaan Bank Syariah (1 ed., Vol. 1). (Q. Media, Penyunt.) Banjarmasin, South Kalimantan, Banjarmasin: Penerbit Qiara Media.

Syafril, \& Huda, N. (2015, Oktober). Analisis Faktor Sosial Budaya dan Psikologis Yang Mempengaruhi Keputusan Nasabah Dalam Memilih Pembiayaan Pada Warung Mikro PT Bank Syariah Mandiri Cabang Banjarmasin. (JWM, Penyunt.) Jurnal Wawsan Manajemen, 3, 257-268.

Tho'in, Y. A. (2018). Meningkat Loyalitas Mahasiswa Melalui Service Performance. Jurnal Relevance, 107-118.

Umam, K., \& Hisyam, F. (2017). Peran Buzz Marketing Dalam Menjaring Siswa Baru di Bimbingan Belajar Alumni Jogja. Diskusi Panale Pendidikan Kewirausahaan (hal. 216227). Jakarta: LPPM Universitas Indraprasta PGRI Jakarta.

Umar, H, 2008, Desain Penelitian Akuntansi Keperilakuan. PT Grafindo Persada, Jakarta Zeithaml, V. A., Parasuraman, A., Berry, L. L., \& Berry, L. L. (1990). Delivering Quality Service: Balancing Customer Perceptions and Expectations. Simon and Schuster. 